\title{
REFLEXIONES SOBRE LA RELACIÓN TEXTO-ESCENA EN EL HORIZONTE TEATRAL POSDRAMÁTICO. EL CASO DE 4.48 PSYCHOSIS DE SARAH KANE
}

\author{
Mariana BLANCO \\ Universidad Nacional de Mar del Plata \\ marublanc@gmail.com
}

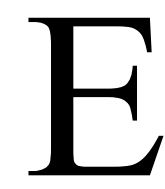

1 presente trabajo propone una breve revisión del concepto de «teatro posdramático», acuñado por el teórico y crítico alemán Hans-Thies Lehmann en su libro homónimo, con el objeto de reflexionar sobre la relación entre el texto y la escena en el panorama teatral contemporáneo y, puntualmente, en la última producción de la dramaturga británica Sarah Kane, 4.48 Psychosis (1999), abordada, cada vez con mayor frecuencia, a la luz de este paradigma. Considerado actualmente un ensayo clave y de referencia obligada, el estudio de Lehmann ha sido traducido a diversos idiomas y, desde su primera publicación en 1999, no ha dejado de suscitar nuevas interpretaciones, reelaboraciones y polémicas que abren interesantes líneas de discusión para indagar en las propuestas más experimentales del teatro reciente.

En consonancia con el avance de los Performance Studies, las reflexiones teóricas de Lehmann surgen de la necesidad de pensar de otra manera el vínculo entre el concepto tradicional de drama y las manifestaciones teatrales «no dramáticas» emergentes en las últimas décadas del siglo XX, sobre todo a partir de los años 70. El autor dirige la atención hacia los materiales, dispositivos y recursos propios del teatro que hacen a la especificidad de su discurso y que, puestos en primer plano, auspiciaron en los últimos tiempos el advenimiento de nuevas formas teatrales, atravesadas por las nuevas tecnologías y los cambios en los modos de percepción, en las que el texto escrito se constituye como un elemento más de la creación escénica total. De este modo, frente a la preeminencia del texto como medio de representación privilegiado por el teatro occidental, en el que la puesta en escena ha sido concebida, principalmente, como ilustración, declamación o actualización del texto escrito, el teatro posdramático, ya no necesariamente sujeto a un soporte textual que funcione como garantía de sentido, se orienta, más bien, hacia una reflexión sobre el problema de la representación y sobre los mecanismos formales de su construcción en tanto práctica escénica. En otros términos, el pasaje hacia el teatro posdramático se produce cuando todos los medios teatrales más allá del lenguaje se encuentran puestos sobre una base de igualdad con el texto, o pueden ser pensados sin él, cuando la escena es 
entendida «como principio y punto de partida» y «no como el lugar de una transcripción» (Lehmann, 1999a: 58).

Ahora bien, tal como ocurriera con la tan discutida noción de posmodernidad ${ }^{1}$, la elección del epíteto «posdramático» generó una serie de controversias por lo que Lehmann se encargó de aclarar que el concepto no debe ser entendido como una categoría epocal, un «después del drama» que supone un olvido o una superación definitiva de la tradición anterior, sino como una tendencia que entabla un diálogo deconstructivo con el pasado dramático y, al verse afectada por los supuestos y convenciones fijados por dicha tradición, entraña un incesante problematización y redefinición del drama mismo. Como observa José Sánchez,

La afirmación de la autonomía [del arte escénico respecto del drama] no constituye en sí misma una negación del texto, ni siquiera del drama [...] El teatro posdramático no es un teatro sin drama, sino un teatro que plantea un conflicto con el concepto burgués de teatro, que había hecho suya la hegemonía del drama literario sobre el espectáculo escénico (2013: 18).

Siguiendo esta línea, Lehmann comienza su análisis de las nuevas formas teatrales entablando una polémica con Peter Szondi, quien, en su seminal ensayo Theorie des Modernen Dramas (18801950) [1956], examina las tribulaciones atravesadas por la forma dramática con el advenimiento del drama moderno. Claramente influenciado por el pensamiento marxista y las obras de Lukács, Benjamin y Adorno, Szondi fue uno de los primeros en diagnosticar la crisis del «drama absoluto» que se produce en las postrimerías del siglo XIX a raíz de una tensión creciente entre los requerimientos formales del género (acción mimética desarrollada en el presente, progresión orgánica de la fábula, relación interpersonal, predominio del diálogo como sostén de la dialéctica intersubjetiva, exclusión de todo elemento ajeno al universo dramático, etc.) y los conflictos del individuo y la sociedad modernos, que ya no pueden ser contenidos por la forma clásica. Dicha fricción entre forma artística y realidad histórica abre una encrucijada en la evolución del teatro europeo que oscila, según Szondi, entre los diversos intentos de «preservación» de la forma dramática tradicional y las «tentativas de resolución» frente a la crisis, tentativas que auspician la incorporación de elementos épicos al drama.

Tomando este panorama como punto de partida, Lehmann considera limitada la visión de Szondi que, basándose en la oposición entre el drama de textura aristotélica y las nuevas tendencias épicas, reduce las metamorfosis experimentadas por las formas teatrales a partir de la transición al siglo XX, a variantes de una «epicización», privilegiando, de este modo, el teatro brechtiano como la mayor ruptura con la tradición. Pese a que posteriormente Szondi, sobre todo en sus estudios sobre el drama lírico, amplió esta tesis inicial que postulaba a la épica como sucesora de lo dramático y como clave para pensar los desarrollos teatrales más recientes, lo que le interesa destacar a Lehmann es que su análisis de la desintegración de la forma dramática a nivel textual constituye tan solo una interpretación parcial que actualmente exige una revisión. Lo que se propone, entonces, el autor alemán es una

\footnotetext{
${ }^{1}$ También la expresión «teatro posmoderno» fue utilizada para describir la plétora y diversidad de fenómenos presentes en el panorama teatral contemporáneo. No obstante, Lehmann insiste en que los recursos puestos en juego en la práctica teatral de las últimas décadas en ningún modo demuestran una renuncia definitiva a los principios de la Modernidad; sí, en cambio, un rechazo contundente de las convenciones formales de la tradición dramática.
} 
comprensión más abarcadora del modo en que este complejo proceso de transformación condujo a un distanciamiento cada vez más pronunciado entre el teatro y el drama, al abandono progresivo de la concepción del teatro como imitación de una acción, como representación de un mundo ficcional cuya clausura estaba garantizada por la forma dramática misma:

[...] el teatro dramático era una maquinaria ilusionista. Se pretendía erigir un cosmos ficticio y presentar las tablas que significan el mundo como representado, abstraído pero establecido de modo que la fantasía y la empatía de los espectadores contribuyeran a una ilusión... La globalidad, la ilusión, la representación del mundo son inherentes al modelo del drama y, a la inversa, el teatro dramático constata, mediante su forma, la totalidad como modelo de lo real. El teatro dramático termina cuando estos elementos dejan de ser el principio regulador y se convierten en una posibilidad entre otras dentro del arte del teatro (Lehmann, 1999a: 37).

Por consiguiente, para Lehmann, el teatro se plantea concretamente las posibilidades que existen más allá del drama cuando el transcurso de una historia con su lógica interna (exposición, acción progresiva, peripecia, catástrofe) deja de constituir el elemento central (1999a: 43); cuando, además de prescindir de la trama, tampoco son necesarios, «ni una colisión dialéctico-dramática de valores, ni siquiera personajes identificables para producir teatro» (1999a: 60).

En este punto, Lehmann reconoce que, efectivamente, ya ciertas manifestaciones del teatro moderno habían puesto en crisis este modelo del drama en aspectos sustanciales, por lo que el teatro posdramático supone la presencia y continuidad de estéticas precedentes y sería impensable, por ejemplo, sin el impulso transgresor de las vanguardias históricas (Simbolismo, Surrealismo, Futurismo, Teatro Dadaísta, etc.), las neo-vanguardias de los 50 y 60 (Existencialismo, Teatro del Absurdo) $\mathrm{y}$, por supuesto, del teatro épico, considerados como valiosos antecedentes que allanaron el camino a las nuevas prácticas experimentales. Sin embargo, el autor está convencido de que, pese a la profunda ruptura originada por dichos movimientos, estos mantuvieron, en mayor o en menor medida, la esencia del teatro dramático ${ }^{2}$, puesto que continuaron subordinándose a la escenificación de mundos textuales y, solo dentro de ciertos límites, cuestionaron el modelo de la representación y la comunicación teatrales (Lehmann, 1999a: 37). El teatro postdramático, por su parte, llevará al extremo la revolución iniciada por las vanguardias, pero lo hará a través de un «ejercicio de afirmación» de la materialidad y la especificidad de los lenguajes escénicos cuyo sentido «no se agota en un gesto de rechazo» (Cornago, 2006: 3). En síntesis, el surgimiento de un discurso teatral multiforme y heterogéneo, característico del paso de la cultura textual a una cultura mediatizada, sumado a la inagotable exploración de nuevas posibilidades para la puesta en escena, ha promovido, en palabras de Lehmann, una «autonomización»o «reteatralización» del teatro que, liberado de su sujeción al discurso literario, busca afirmarse como práctica artística independiente.

\footnotetext{
${ }^{2}$ La fórmula «Teatro dramático» opera aquí como síntesis del paradigma que definió el teatro europeo moderno, entendido tácitamente como «teatro de dramas», y fue empleada, asimismo, por el propio Brecht para aludir a la tradición que su teatro épico pretendía subvertir. Sin embargo, afirma Lehmann, ciertos componentes inherentes al drama, por ejemplo la fábula como condición sine qua non, sobreviven en el teatro brechtiano, por lo cual la vertiente épica sería más bien una desviación temprana, un impulso avant la lettre en la transformación de la estructura dramática.
} 


\section{«Just a word in a page and there is the drama». El caso de 4.48 Psychosis de Sarah Kane}

Teniendo en cuenta las apreciaciones sintetizadas en el apartado anterior, nos proponemos, a continuación, problematizar la inscripción del teatro de Sarah Kane (Essex, 1971 - Londres, 1999) en el denominado paradigma posdramático, considerando el creciente interés por este enfoque que se aprecia en los estudios más recientes acerca de la obra de la dramaturga británica. Nos detendremos especialmente en el análisis de 4.48 Psychosis, puesto que en esta, su última pieza, la autora lleva al extremo el trabajo de experimentación con la forma dramática, rasgo que se constituye como uno de los más singulares de su poética.

En efecto, Kane revolucionó la escena alternativa londinense con el estreno de Blasted (1995), un típico drama doméstico de resonancias ibsenianas que, tras la explosión de una bomba en la tercera escena, se transforma en un universo brutal, surrealista y apocalíptico, inspirado en los horrores del conflicto de Bosnia. En esta pieza, la autora busca recrear el caos y los estragos de la guerra mediante una manipulación deliberada de las convenciones del realismo social, todavía vigentes en la dramaturgia británica desde la posguerra (Saunders, 2002). Kane seduce engañosamente al espectador con las intrigas sexuales de una pareja de amantes, para luego confrontarlo, sin ninguna explicación lógica, con los efectos devastadores de la violencia que estalla directamente frente a sus narices junto con la estructura de la «well-made play». Tan revulsiva por sus transgresiones formales como por las inquietantes problemáticas que explora, la obra desató una oleada de «hysterical reviews» (Saunders, 2002) y pronto se vio envuelta en un escándalo mediático que suscitó reacciones encontradas por parte del público y de la crítica especializada

En una década en que la dramaturgia de autor estaba atravesando un período de crisis y reclamando la emergencia de nuevas voces, la repercusión del debut de Kane colocó nuevamente al teatro en el centro del debate cultural y dirigió la atención hacia una generación de jóvenes escritores cuyas obras impulsaban la revitalización del género. El nuevo drama, entre cuyos autores se destacan Philip Ridley, Anthony Neilson y Mark Ravenhill, procuraba romper todos los tabúes, invadir el espacio personal del espectador, cuestionar sus valores morales y los supuestos que sustentaban su percepción de la realidad, mediante un lenguaje revulsivo y una imaginería extremadamente violenta, explícita y provocadora. De ahí que Sierz propusiera la etiqueta de «In-Yer-Face Theatre» ${ }^{3}$ en una tentativa por describir la naturaleza esencialmente desafiante de la nueva estética, a diferencia de otras denominaciones como «New Brutalists», que se basaban fundamentalmente en el contenido de las obras.

Tras la tormentosa acogida que tuvo Blasted, Sarah Kane fue proclamada como una de las principales exponentes del In-Yer-Face, «the most famous and infamous playwright of the 1990s» (Rees, 2012: 112). No obstante, como posteriormente se ha reconocido, su obra excedió las categorías reduccionistas acuñadas por la crítica. Si bien es innegable que sus primeras piezas presentan rasgos afines a la nueva sensibilidad, su escritura, que se desarrolló vertiginosamente en un período de cinco

\footnotetext{
${ }^{3}$ Deformación de «In Your Face» («En tu cara»), expresión que comenzó a utilizarse a mediados de los 70 en el ámbito del periodismo deportivo, como una manifestación de escarnio, provocación o desdén.
} 
años, se orientó hacia formas cada vez más experimentales que la condujeron por derroteros muy diferentes a los de sus contemporáneos. El estreno de Crave, su penúltimo trabajo, significó una transformación rotunda en la poética de la autora («a linguistic turn», tal como lo define, entre otros, Lauren de Vos) y un desvío definitivo del brutalismo feroz característico del nuevo drama, algunos de cuyos representantes se mantuvieron atados a las convenciones del realismo o imitaron los mecanismos de representación de los mass media (Urban, 2001). En Crave, la dramaturga abandona la escenificación de la violencia física característica de sus obras tempranas, cifradas en el impacto de la gestualidad, el movimiento escénico y la imagen visual, para replegarse obsesivamente sobre el lenguaje y explorar nuevas posibilidades de la expresión teatral.

En este marco, mientras algunos autores como Ahmet G. Biçer no dudan en afirmar que «Kane's theatre is totally a postdramatic one as Hans-Thies Lehmann characterizes» (Biçer, 2011: 1), hay quienes se muestran más reacios a aceptar, sin más, esta aserción. Una de las principales objeciones que plantea cierto sector de la crítica al momento de abordar el teatro de Sarah Kane desde el enfoque posdramático es, tal como señala Catherine Rees, la centralidad que adquiere el componente textual en la producción de la autora y, sobre todo, en su última pieza, 4.48 Psychosis, cuyo complejo diseño formal se sostiene en un cuidado y minucioso ejercicio de experimentación con la palabra. En la misma línea, Eckart Voigts-Virchow afirma que «one of the most obvious areas in wich Kane and postdramatic theatre seem incompatible is the notion of writing» (2010: 199). Voigts-Virchow llama la atención sobre el hecho de que, en el ámbito británico, dominado por la dramaturgia de autor, el texto se constituye como pieza clave del dispositivo teatral, circunstancia a la que tampoco es ajena, pese a su «anathematic position» ${ }^{4}$ con respecto al teatro hegemónico, la obra de Kane, quien no solo desarrolló su formación académica en el campo de la escritura dramática, sino que trabajó como escritora residente o asesora literaria en diversas salas de la escena alternativa londinense.

Partiendo de esta asunción, y sin dejar de conceder que «Crave and 4.48 Psychosis are clear emanations of a post-dramatic theatrical sensibility [...] and may stand the test of time as richer or more "avant-garde" texts» (2010: 206-207), Voigts-Virchow postula que, a juzgar por las reacciones provocadas, pareciera que, en realidad, fueron las primeras piezas de la autora las que cuestionaron con mayor contundencia el modelo dramático a través de la desfiguración hiperbólica, el exceso y el poder disruptivo y alienante de la violencia, mientras que los juegos verbales y el minimalismo beckettiano de las obras finales, acogidos con mayor entusiasmo tanto por el público como por la crítica, «could be much better incorporated in a theatrical tradition» (2010: 203).

Coincidimos, en parte, con este autor cuando observa que los tres primeros trabajos de Kane, con su espectacular despliegue de la brutalidad en escena, apelaban a un impacto afectivo más inmediato sobre la sensibilidad de la audiencia y, por esta razón, pueden llegar a resultar más controversiales, transgresores y arriesgados que las dos obras posteriores, llamadas «lingüísticas». Sin embargo,

\footnotetext{
${ }^{4}$ Voigts-Virchow se apropia aquí de una línea del texto de 4.48 Psychosis: «We are anatema / the pariahs of reason», y utiliza esta expresión para aludir a la posición excéntrica, marginal, de Kane en el campo teatral británico, fundada en la reputación de autora maldita, de enfant terrible, que alcanzó la dramaturga, sobre todo a partir del escándalo de Blasted.
} 
consideramos que, por el solo hecho de haber tenido una mayor aceptación, estas últimas no han perdido su fuerza revulsiva y desestabilizadora puesto que, aunque pongan en funcionamiento estrategias diferentes, ambos textos entrañan un profundo desafío emocional e intelectual para el espectador. Por otra parte, no se puede dejar de insistir, de acuerdo con la dirección que sigue nuestro análisis, que, si ya en Blasted se insinúa un primer desvío de las convenciones del drama tradicional que anticipa el rumbo que tomará la dramaturgia de Kane, en lo que concierne al aspecto formal, el proceso de descomposición de los fundamentos constitutivos del paradigma dramático alcanza su máxima expresión en la etapa final de su producción. Esta cuestión no pasa desapercibida para VoigtsVirchow que, más allá de sus hesitación en torno a la relación entre el teatro de Kane y el fenómeno posdramático, advierte: «One may argue that Kane, al least up to Crave, adhere to basic categories of dramatic writing, to the "as if" [mimetic] mode: she introduced characters [...] impersonated by actors, and she involved them in a narrative, however disruptive it may seem» (2010: 200). Por su parte, la propia Kane, quien fue además directora y actriz, por lo que tenía una clara comprensión de los alcances del hecho teatral, declaró que pensaba en Crave «more as a text for performance than as a play» (cit. en Saunders, 2002: 17).

La distinción que hace la autora adquiere una especial resonancia cuando nos acercamos a un texto como el de 4.48 Psychosis, en el que, más allá de algunos diálogos dispersos, ya no es fácilmente reconocible la típica notación dramática, con su división en actos y escenas y su doble textualidad (texto didascálico/discurso de los personajes). Kane suprime deliberadamente las acotaciones espaciotemporales, los dramatis personae y toda indicación que permita determinar cuántos personajes intervienen en escena. Es más, cabe preguntarse si, en el caso de 4.48 Psychosis, todavía es posible hablar de «personaje» en sentido tradicional, pues este, despojado de antemano de todo rasgo específico que contribuya a individualizarlo y a autentificar su pertenencia a la realidad socio-histórica, se presenta aquí como una «encrucijada de palabras» (Ryngaert, 2001), palabras de orígenes diversos que no hacen más que acentuar la fractura entre sujeto y lenguaje.

Tampoco se plantea, desde el plano textual, una «situación dramática» (Pavis, 1996) que ayude a contextualizar los parlamentos extraviados de esa voz o, mejor, de esas voces sin nombre que, separadas del fundamento de una identidad definida, parecen pronunciarse desde el vacío. No obstante, los breves pero insistentes comentarios autorreferenciales diseminados en el nivel del enunciado insinúan algunas posibles claves de lectura: «a consolidated consciousness resides in a darkened banqueting hall $[\ldots]$ when a shaft of light enters and all thoughts unite in an instant» (Kane, 2001: 205), «my mind is the subject of these bewildered fragments» (Kane, 2001: 210). Para Graham Saunders, son las palabras finales de la pieza ( «It is myself I have never met, whose face is pasted on the underside of my mind» [Kane, 2001: 245]) las que permitirían establecer que todas las voces pertenecen a un mismo sujeto sumido en la dolorosa búsqueda de su propio Yo (Saunders, 2002: 113).

Siguiendo esta línea, 4.48 Psychosis puede ser leída, en sus claras filiaciones con el expresionismo, como la puesta en escena del tumulto interior de una conciencia, abismada por la enfermedad, que, en diálogo consigo misma o con esas otras voces de la locura, testimonia balbuceante su pronta 
desaparición. Como un gran monólogo habitado en el que las fronteras entre el yo y el mundo exterior, entre la realidad, el sueño y la alucinación, se vuelven inestables al punto de desvanecerse y, en consecuencia, ya no es posible precisar quién o quiénes hablan. La estructura fragmentaria del texto, construido a partir del montaje y reelaboración de diversos materiales discursivos que se yuxtaponen al ritmo del fluir errático de la conciencia, intensifica el efecto de indiscernibilidad entre las diferentes voces, al tiempo que busca recrear la disforia, el desorden mental anticipado por el título de la pieza. Esta colección de fragmentos, reunidos aparentemente en forma aleatoria, pero claramente separados por líneas punteadas que podrían funcionar como cortes que marcan el pasaje de una escena a otra, incluye sesiones de psicoanálisis, conversaciones entre psiquiatra y paciente, soliloquios líricos, reescrituras del texto bíblico, enunciados numéricos ininteligibles, largas secuencias y listas de palabras, abreviaturas, citas extraídas de libros de psicología y autoayuda, segmentos de historias clínicas, etc. En este sentido, 4.48 Psychosis puede también pensarse como una vertiginosa sucesión de cuadros que, subvirtiendo las reglas de la progresión de la trama, se conectan y resignifican entre sí, y que bien podrían ser interpretados por diferentes actores.

Como sea, las estrategias desplegadas por Kane para escenificar una realidad que, por su misma naturaleza, no podría ser presentada sin un grado de caos o confusión, obedecen a su propósito de hacer colapsar formalmente ciertos límites «to carry on with making form and content one» (cit. en Saunders, 2002: 112). El lema «The form is the meaning» sintetiza el credo estético de la autora y se constituye, asimismo, como uno de los principios fundantes del teatro posdramático que ya no pretenderá ocultar sus artificios, disimular sus procedimientos, con el objeto de que estos desaparezcan detrás de la representación, «como meros recursos para ilustrar una acción cargada de tensión» (Lehmann, 1999a: 62)

En efecto, pese a que «a residual notion of fiction may be detected even in the narration of 4.48 Psychosis» (Voigts-Virchow, 2010: 205), lo cierto es que la anécdota, la historia, tal y como ha servido de apoyatura y de elemento estructurador en el teatro occidental (Talens, 1987: 11), no solo aparece aquí absolutamente desbaratada sino que el propio texto se encarga de cuestionar su misma posibilidad: «I have reached the end of this dreary and repugnant tale of sense» (Kane, 2001: 214). Al respecto, es importante considerar el lugar y la función que la autora otorga a la catástrofe, ya no como clausura de la trama, sino como condición previa, inaugural, de un «drama sin solución» (Sarrazac, 2011) que, en consecuencia, se verá trastornado en todos sus fundamentos constitutivos. Si, como sostiene Abirached, la ruina de la fábula es inseparable de la crisis del personaje, concebido tradicionalmente como el dispositivo estructural que organiza las etapas del relato (Pavis, 1996), no resulta difícil comprender las razones por las que la acción, la gran acción como sistema orgánico, deviene imposible para el/los personaje/s ya no actuantes sino agonizantes de Kane. Como señala Joseph Danan a propósito de Crave:

Quizás aquí la acción tenga dificultades para conservar ese nombre y en los casos extremos de los tropismos textuales, interiores o exteriores, llevados por las palabras (Ansia de Sarah Kane), tal vez lo mejor sea hablar de un «principio activo» difuso, una energía — que tendría que ponerse en relación con el ritmo-, 
manteniendo por ahora esas obras al interior de una forma dramática que no cesa de empujar sus límites (2001: 40-41).

El debilitamiento o, mejor, la interrupción, del «continuum fabular» (Sarrazac, 2011) no impide, entonces, que otra especie de acción, la de la palabra, prolifere, desencadenando un movimiento desarticulado, discontinuo, que no progresa linealmente sino por medio de variaciones, repeticiones y antítesis. En este contexto, los bruscos cambios de tono, la transición de un fragmento a otro que se produce sin ninguna conexión lógica, apuntan a generar un efecto de perplejidad y desconcierto en el espectador, cuya percepción de la escena, ya no controlada por la coherencia interna de una narración dramática, se verá permanentemente desestabilizada por estos violentos contrastes. Baste comparar, a modo de ejemplo del carácter disonante de este collage textual que es 4.48 Psychosis, la modulación poética y oscura de la imaginería bíblica que emerge en los extravagantes delirios místicos del yo, con el lenguaje deshumanizado del discurso médico-psiquiátrico de la secuencia correspondiente a la historia clínica:

Why am I stricken?

I saw visions of God

[...] Behold the light of despair the glare of anguish and ye shall be driven to darkness

If there is blasting (there shall be blasting)

The names of offenders shall be shouted from the rooftops

Fear God

And his wicked convocation (2001: 228)

Symptoms: Not eating, not sleeping, not speaking, no sex drive, in despair, wants to die.

Fluoxetine hydrochloride, trade name Prozac, 20mg, increased to 40mg. Insomnia, erratic appetite, (weight loss $14 \mathrm{kgs}$.), severe anxiety, unable to reach orgasm, homicidal thoughts towards several doctors and drug manufacturers. Discontinued.

[...] 100 aspirins and one bottle of Bulgarian Cabernet Sauvignon, 1986. Patient woke in a pool of vomit and said 'Sleep with a dog and rise full of fleas'. Severe stomach pain. No other reaction (2001: 223225).

Como ya se evidencia en las citas anteriores, además de la reescritura paródica que Kane, con su característico humor corrosivo, hace de estos formatos textuales, la autora trabaja con la dimensión espacial de la escritura, explotando la productividad significante de la distribución de los signos y los blancos en la página. Introduce en el texto diferentes tipografías y juega con la disposición visual de los números y las palabras sueltas, que aparecen en series, en listas o en cascada, o bien diseminados de manera totalmente azarosa. Dichos procedimientos, sumados a la exploración de las potencialidades sonoras y rítmicas del lenguaje, acercan el diseño formal de la pieza al de un extenso poema vanguardista, lo que ha llevado de manera recurrente a la crítica a poner en entredicho su teatralidad, 
en una lectura que pone de manifiesto hasta qué punto los cánones y expectativas del teatro dramático continúan fuertemente arraigados en la concepción del texto teatral (Lehmann, 1999: 87).

Estos últimos aspectos son también retomados por Catherine Rees para quien, como ya señalamos, la dificultad de analizar 4.48 Psychosis en relación con el teatro posdramático reside precisamente en el carácter «highly (self-consciously) textual, almost poetic» (2012: 131) de la obra, lo que entraría en conflicto con los postulados de Lehmann, (mal)interpretados aquí como una negación general del teatro de texto. Por consiguiente, consideramos necesario introducir algunas precisiones sobre esta cuestión.

Por un lado, como antes señalamos, la cualidad lírica de la pieza es indiscutible, así como el valor que Kane otorga al dispositivo literario-textual. Si nos remitimos a la cita elegida como título de este apartado, «Just a word in a page and there is the drama» (2001: 213), podemos advertir que esta cuestión aparece problematizada en el texto mismo. Para Rees, la autora parece sugerir a través de esta breve sentencia que el drama «is constructed thought the words provided on the page - that the experience of reading or performing them creates the theatrical event» (2012: 133). Saunders, por su parte, ve en esta línea del texto una clara refutación de la opinión de ciertos críticos «who showed scepticism over whether 4.48 Psychosis constituted a performance text» (2009: 35). Desde nuestra perspectiva, y para evitar el riesgo de incurrir en una sobreinterpretación de su sentido, lo interesante de estas alusiones metateatrales es que someten el universo ficcional a «continuas aperturas hacia lo real» (Abuín González, 2006:160), auspiciando, entre otras cosas, la emergencia de un espacio autobiográfico $^{5}$ en el que se configura una determinada imagen autoral y, paralelamente, se delinea una poética de escritura:

They know nothing-

I have always walked free

Last in a long line of literary kleptomaniacs

(a time honoured tradition)

Theft is the holy act

On a twisted path to expression (2001: 213).

En una declaración no exenta de ironía, Kane se (auto) construye, desde el discurso ficcional, como una cleptómana literaria, asumiendo que la labor creadora de todo escritor entraña una constante apropiación o, podríamos decir, un saqueo legitimado de elementos de una vasta tradición. Y si bien, en el caso de esta autora, dicha apropiación se esgrime como una estrategia consciente que se hace extensiva a toda su producción, es en 4.48 Psychosis donde se vuelve ostensible al ser exhibida, en primer plano, como el procedimiento privilegiado de construcción del texto.

\footnotetext{
${ }^{5}$ Esto no equivale a afirmar, sin ambages, que «el personaje es la escritora» (Rosenzvaig, 2009: 95). Si bien no es nuestro interés aquí problematizar las interpretaciones en clave autobiográfica del texto, cabe mencionar, al respecto, que Kane terminó 4.48 Psychosis meses antes de quitarse la vida en el King's College Hospital de Londres. Este episodio, corolario de un estado depresivo severo con el que la dramaturga lidió durante años, no solo contribuyó a consolidar el mito construido en torno a su nombre, sino que atravesó como una estela imborrable la lectura de su última pieza, estrenada en forma póstuma en 2000 y frecuentemente analizada como una recreación poética de su tragedia personal.
} 
Este gesto autorreflexivo es uno de los mecanismos ponderados por la nueva escritura teatral que, según Poschmann, continuamente refleja su constitución como constructo lingüístico y ya no es, en muchos aspectos, una escritura «dramática», en tanto los «principios de narración y figuración, asî como el orden de la fábula» desaparecen, dando lugar a una «autonomía del lenguaje» (cit. en Lehmann, 1999a: 30). Dicho proceso es decisivo al momento de pensar los alcances que adquiere en 4.48 Psychosis el trabajo con la palabra poética, cuestión en la que profundizaremos más adelante, puesto que, como observa el propio Lehmann:

Retaining the dramatic dimensión to different degrees, Werner Schwab, Elfriede Jelinek, Rainald Goetz, Sarah Kane and René Pollesch [...] have all produced texts in wich language appears not as the speech of characters-if there still are definable characters at all-but as an autonomous theatricality (1999b:18).

Por otra parte, si bien es cierto que el objeto de investigación de Lehmann abarca fundamentalmente un efímero repertorio de prácticas teatrales, quizás solamente recuperables y de manera precaria en la memoria del espectador, el autor insiste en que el plano textual no ha desaparecido de la escena contemporánea, cuya reivindicación de la experiencia escénica no implica que los textos escritos para el teatro ya no sean significativos o no puedan ser analizados en este marco. Por tal motivo, dedica un apartado de su libro al estudio de la nueva escritura teatral en el que no deja de considerar a ciertos autores cuyas producciones son particularmente afines al paradigma posdramático. Sin ir más lejos, en el prefacio a la traducción inglesa de su estudio publicada en 2006, menciona a Kane y, específicamente, se refiere a 4.48 Psychosis como «one of the great texts in analogy to postdramatic theatre» (1999b).

Quizás el verdadero problema consista, entonces, en que la crítica o bien ha recurrido a la categoría de lo posdramático o bien ha cuestionado su pertinencia para delimitar en sí misma una dramaturgia o poética de escritura, desatendiendo el hecho de que este enfoque, si no desestima el trabajo con el texto, apunta a promover el abordaje de la dimensión textual desde la perspectiva de la realidad teatral. Como sostiene Cornago, la noción de teatro posdramático designa ante todo «"un modus operandi", una manera de entender la creación escénica — y por extensión la misma realidady su construcción/comunicación como proceso» (2006: 3). Esto no significa «que no sea posible definir ciertos procedimientos característicos de los textos posdramáticos, pero se trata de una caracterización a nivel estructural que determina el funcionamiento de esos textos (incluso en su lectura) antes que una poética determinada» (2005: 5). Cornago distingue entre los rasgos generales del «texto posdramático $»^{6}$ (rasgos que, en última instancia, pueden concretarse en poéticas diferentes): la fragmentariedad, la escasez de diálogos realistas, la ausencia de personajes y acciones claramente definidos y, en contraste con las observaciones de Rees, la emergencia de un tono fuertemente poético.

Como podemos apreciar, entonces, lo posdramático se presenta como una noción problemática, ambigua, que ha sido objeto de interpretaciones diversas, pero lo que nos interesa resaltar es que esta categoría no puede reducirse a la fórmula «verbal»versus «averbal», a la consabida oposición entre

\footnotetext{
${ }^{6}$ Para evitar el oxímoron, la contradicción inherente a esta expresión, Lehmann preferirá hablar de «textos teatrales no dramáticos» o bien de «textos organizados de modo posdramático» (Lehmann, 1999: 30-31).
} 
«teatro textual»y «teatro vanguardista»(Lehmann, 1999: 256). Apartándose de este esquema, el teatro posdramático continúa la línea abierta por el théâtre de la cruauté artaudiano puesto que, como proclamaba Artaud en sus intentos por redefinir la práctica teatral, no se trata de desterrar definitivamente la palabra de la escena, tampoco de «una simple alternativa a favor o en contra del texto», sino más bien «de un desplazamiento de la jerarquía, de la apertura del texto, de su lógica y de su arquitectura forzadas» a fin de que el teatro recupere su dimensión de acontecimiento (Lehmann, 1999a: 256).

Por lo tanto, lo que está en juego aquí es una cuestión sobre la que, a nuestro entender, la crítica no ha hecho suficiente hincapié, es decir, qué relación con la escena, qué concepción del acontecimiento teatral se diseña implícitamente en la pieza de Kane o en qué medida esta socava la forma dramática tradicional, planteando, por esto mismo, interesantes desafíos para su realización. Al respecto, es posible discutir con Voigts-Virchow cuando concluye: «It is in fact in her confrontational, antagonistic and demanding stage directions, rather in their almost complete absence or graphemic transformation into dashes and poetic indentions in Crave and -more particularly- 4.48 Psychosis, that a post-dramatic otherness is preserved» (2011: 207). Sin lugar a dudas, la imaginería desplegada en las primeras piezas de Kane, para quien no existe limitación alguna en cuanto a las posibilidades que ofrece el escenario, exige una intervención radical por parte de directores y actores, compelidos, como destaca David Creig, «to go to the limits of their theatrical imagination, forcing them into poetic and expressionist solutions» (2001: xiii). No obstante, también es importante advertir que la abundancia de acotaciones en los primeros trabajos de la autora entraña un gesto de control ejercido desde el texto, en tanto el mismo texto proporciona, por momentos con exhaustiva precisión, las directrices de su tratamiento escénico ${ }^{7}$.

$\mathrm{Si}$, como ya aclaramos, para el teatro posdramático el hecho teatral no se reduce a la ilustración del texto escrito, entonces, de acuerdo con la perspectiva de Cornago, un texto afín a este tipo de práctica ya «no tendrá las marcas representacionales que sí podemos detectar en otros textos pensados para prácticas escénicas distintas» (2006: 5). En este sentido, consideramos que los retos que plantea una «pieza» como 4.48 Psychosis ya no pueden resolverse fácilmente en términos de drama o dramaticidad, puesto que, lejos de constituir una obra lingüística acabada y perfecta, según el modelo dramático tradicional, el texto se ofrece, antes bien, como un material desconcertante y problemático para la escena. En palabras de Lehmann:

El nuevo teatro hace más evidente algo que se conocía desde hace tiempo atrás: que entre el texto y la escena nunca existió una relación armónica, sino más bien un conflicto constante. [...] Ya que esta circunstancia es un conflicto estructural latente en cualquier práctica del teatro, ahora se puede convertir en un principio de escenificación intencionado (Lehmann, 1999a: 256).

En consonancia con lo anterior, el autor alemán distingue como una constante de las prácticas emergentes en el horizonte teatral contemporáneo la redefinición del plano textual como una «chora-

\footnotetext{
${ }^{7}$ Cabe señalar que, desde luego, esta construcción implícita del acontecimiento, diseñado en la micropoética del texto dramático, no coincidirá necesariamente con los acontecimientos escénicos históricos (Dubatti, 2010).
} 
graphía» $^{8}$ (1999a: 257) en la que la sensualidad de la palabra, el ritmo, la respiración, el ruido, el tartamudeo, sumados a la presencia visceral de los cuerpos en escena, se imponen sobre la bella perfección del lenguaje, sobre el discurso fundado en el logos:

Aquello que se perfila en el nuevo teatro, así como en las tentativas radicales de la langue poétique de la modernidad, se puede entender consiguientemente como un intento de restitución de la chora: un espacio y un discurso sin thelos, sin jerarquía, sin causalidad, sin sentido fijable y sin unidad. [...] Por tanto, el estatus del texto en el nuevo teatro puede describirse mediante los conceptos de deconstrucción y polilogía. [...] No se aspira al diálogo sino a la multiplicidad de voces (Lehmann, 1999a: 257-258).

En virtud del fenómeno descrito, que expresa los límites de la función representativa del lenguaje, la palabra significante tiende a convertirse en una «danza de gestos lingüísticos», en una «teatralidad autónoma» (Lehmann, 1999a: 256). Emerge en escena como un cuerpo extraño, como un objeto expuesto en toda su amplitud, en tanto la frase, el tono, los sonidos, los silencios ya no son controlados por un sentido unívoco o por el diálogo como forma codificada de la comunicación dramática. Al respecto, no se puede dejar de mencionar que en esta concepción teatral del lenguaje, que Lehmann postula como característica del teatro posdramático, es reconocible, una vez más, la deuda que el teórico alemán mantiene con Artaud, quien, como apuntamos antes, ya había planteado la necesidad de repensar el papel del discurso verbal en el hecho teatral, de forzar al lenguaje «a expresar lo que habitualmente no expresa» (1935: 40), alterando la posición de la palabra y utilizándola «de modo concreto y espacial [...] como un objeto sólido que trastorna el estado de las cosas» (1935: $64)$.

Indudablemente estas observaciones posibilitan un nuevo acercamiento al paisaje textual de 4.48 Psychosis y al tratamiento sensorial e intensivo que Kane impone al lenguaje, sometiendo la propia lengua, «órgano del Sentido» (Deleuze-Guattari, 1975), a una variación anómala con respecto a su uso ordinario, privilegiando no tanto el valor referencial de la palabra, como su poder sugestivo y perturbador. El ritmo pulsional que anima ciertos pasajes del texto, en los que el material lingüístico, libre de toda gramática (Spregelburd, 2009), ha sido cuidadosamente escogido en función de su musicalidad, reenvía a la concepción de la palabra-exorcismo o palabra-encantamiento artaudiana, orientada a auspiciar otra forma de comunicación entre la escena y la audiencia, una especie de conexión mágica, visceral, que trasciende la especulación racional:

flicker punch slash dab wring press burn slash
press slash punch flicker flash press burn slash
dab flicker float flash flicker dab press burn slash
pres slash punch flash flicker burn (Kane, 2002: 232).

Kane inicia con Crave la búsqueda de un lenguaje afectivo en el que el que las fracturas de la sintaxis, la amputación de la frase y, sobre todo, el juego con el sonido y el ritmo van a desencadenar

\footnotetext{
${ }^{8}$ Lehmann recupera aquí la definición kristeviana de la «xora semiótica» como un receptáculo (según la acepción que del término da Platón), una instancia anterior al lenguaje, asociada específicamente a lo materno abyecto, en la que reina lo pulsional, lo preverbal, y opuesta al orden simbólico, vinculado a la función fálica, que permite la constitución del sujeto como tal.
} 
«una desorganización activa de la expresión y, por reacción, del contenido mismo» (Deleuze-Guattari, 1975: 45). Ciertamente, esto provoca una escisión, abre una grieta entre el personaje hablante y esa palabra extraña que escapa a su dominio, que se libera y disemina en el espacio eludiendo su función meramente comunicativa y la univocidad del mensaje verbal. Dicho proceso, que Poschmann define como una «autonomización del lenguaje», subvierte el imperativo lógico-lingüístico de la identidad poniendo en evidencia el carácter inestable y problemático de toda construcción identitaria: «Así pues, en los textos organizados de modo posdramático, en lugar de echar de menos una imagen predefinida del ser humano, deberíamos preguntarnos qué nuevas posibilidades de pensamiento y de presentación proponen para el sujeto individual» (Lehmann, 1999a: 31)

En efecto, el/los personaje/s de Kane, tan extraños para el espectador como para sí mismos, se constituyen en escena a través de una palabra descentrada, en un movimiento de diversificación continua que los arrebata y arroja fuera de sí. De este modo, la subjetividad estallada de 4.48 Psychosis, incapaz de afirmarse a través del lenguaje, de reencontrar la unidad y reconocer los límites que la separan del otro, actúa diversos roles, trasvasa su discurso de la primera a la segunda y a la tercera persona, deviene intensidades, «acontecimientos lingüístico-poéticos» (Dubatti, 2009), hasta que la voz se fragmenta y desintegra cada vez más, precipitándose en el espacio (también resonante) del silencio:

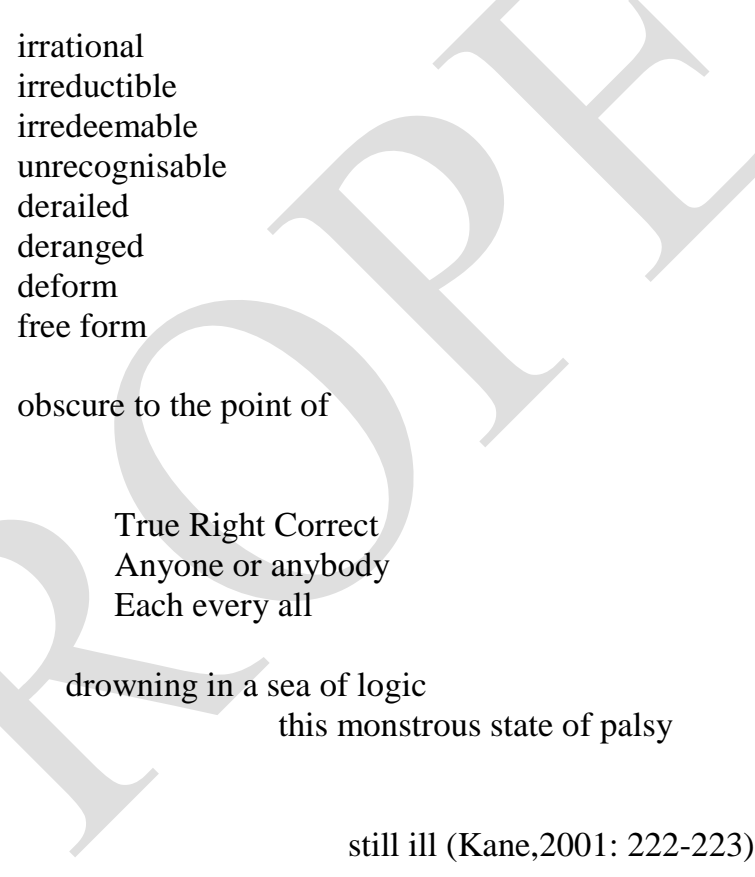

Sometido a la experiencia de esta suerte de «shock de percepción lingüística» (Lehmann, 1999a: 258), que desestabiliza la coherencia del mundo representado, también el espectador se verá, entonces, comprometido afectivamente en el acontecimiento teatral, cuya característica esencial es que su sentido está siempre por producir(se) (Abuín González, 2006: 160). Por eso, Karen Jürs-Munby no duda en incluir a Kane entre aquellos escritores posdramáticos que proponen lo que podría denominarse «open o writerly texts» para la performance. Textos que instan a los espectadores a volverse co- 
escritores de la creación escénica, a reflexionar sobre su propia construcción del significado y, en ocasiones, a tolerar las lagunas y suspender la asignación del sentido. Jürs-Munby recupera la noción barthesiana de «texte scriptible» para sintetizar el carácter performativo, procesual y colectivo de la nueva escritura teatral que involucra al receptor ya no como «consumidor, sino como productor del texto» (Barthes, 1970: 2)

Ahora bien, más allá de estas reflexiones, y puesto que hemos afirmado que el teatro posdramático debe ser entendido ante todo como un «modus operandi», cabe advertir, siguiendo a Cornago, que, en el contexto de la práctica escénica, es igualmente posible que una obra clásica reciba un tratamiento posdramático o, a la inversa, que un texto fragmentario, poético y carente de una acción orgánica como 4.48 Psychosis, sea ilustrado escénicamente de manera representacional, a través de una puesta más o menos convencional. Así, mientras Voigts-Virchow, evocando la producción de 4.48 Psychosis realizada en Frankfurt por Wanda Golonka (ex asistente de Pina Bausch) con su compañía de danza teatro, sugiere que nada impide que el texto de Kane sea transformado en teatro posdramático, Cornago dirá que, en todo caso, lo contradictorio sería aplicar una práctica teatral tradicional a un texto de estas características. En este punto, no está de más insistir en que, por su naturaleza liminal, que descansa en una tensión permanente entre lo dramático y lo no-dramático, la pieza de Kane se resiste a todo intento de categorización. No obstante, dado que nuestro objeto no ha sido otro que el de desentrañar algunos de sus mecanismos experimentales a la luz de las teorizaciones de Lehmann, no parece desacertado concluir que ciertas escrituras, fundadas en un profundo cuestionamiento del lenguaje racional como instrumento de comunicación y en la puesta en crisis de los modelos tradicionales de representación, resultan especialmente propicias para su inserción en la escena posdramática.

Para finalizar, nos interesa retomar las apreciaciones de Jorge Dubatti, quien, en su prefacio a la traducción española de Crave y 4.48 Psychosis, expresa, en otros términos, algunas de las inquietudes expuestas hasta aquí:

Su dramaturgia, y especialmente las piezas aquí incluidas, proponen un nuevo concepto de obra dramática, caracterizado por la complejidad, la indeterminación genérica y el cruce con otras modalidades discursivas. La escritura de Kane es sincrónica con las nuevas formas de registrar literariamente el acontecimiento escénico y con el desafío para los directores de descubrir teatralidad en lo aparentemente no teatral (2009: 10; la cursiva es nuestra).

Y es allí, en esa supuesta no teatralidad, que ha llevado a la crítica a insistir en el carácter irrepresentable de los trabajos de Kane, donde la tensión entre el plano textual y el plano escénico se vuelve singularmente productiva desde el enfoque discutido en este análisis, ya que, como hemos subrayado previamente, la escena se piensa y se reafirma, desde el propio texto, como una práctica «cuyo resultado y proceso de construcción ya no está previsto ni contenido en el texto dramático» (Cornago, 2006: 3). En síntesis, más allá de la importancia que Kane como dramaturga pudo atribuirle a la dimensión literaria-textual del teatro, la evolución que experimenta su escritura la condujo a una apertura y redefinición del texto en la que subyace una concepción del acontecimiento teatral como instancia autónoma, de genuina y libre creación, de indagación y experimentación constantes. Esto se vuelve más evidente en 4.48 Psychosis, un texto en el que se han suprimido las matrices de 
representatividad que controlen o dirijan la puesta en escena y en el que la voz autoral se desvanece como sustrato u origen del sentido escénico, tal como lo demuestran las diversas e innovadoras lecturas que han hecho actores, directores y realizadores en sus numerosas y tan disímiles producciones. Un texto que, al tiempo que cuestiona y problematiza sus propias condiciones de escenificación, insta a la exploración y al descubrimiento de nuevos modos de expresión para el arte teatral, a la búsqueda de un teatro que no cese de interrogarse y de transgredir sus propias fronteras.

\section{Referencias bibliográficas}

ABIRACHED, Robert (1978): La crisis del personaje en el teatro moderno. Trad. Borja Ortiz de Gondra. Madrid, ADE, 2011.

ABuín GonZÁLEZ, Anxo (2006): Escenarios del caos. Entre la hipertextualidad y la performance en la era electrónica. Valencia, Tirant Lo Blanch.

Artaud, Antonin (1935): El teatro y su doble. Trad. Equipo Editorial. Buenos Aires, Retórica, 2002. BARTHES, Roland (1970): S/Z. Trad. Nicolás Rosa. Buenos Aires, Siglo XXI, 2004.

BIÇER, Ahmet G. (2011): «Sarah Kane's postdramatic strategies in Blasted, Cleansed and Crave», Uluslararast Sosyal Ara tırmalar Dergisi. The Journal of International Social Research, 4/17, en http://www.sosyalarastirmalar.com/cilt4/sayi17pdf/1diledebiyat/bicer_gokhan.pdf (última consulta, 4-6-2016).

CORnAGO, Oscar (2006): «Teatro postdramático: Las resistencias de la representación», en José Antonio SÁNCHEZ, dir., Artes de la escena y de la acción en España 1978-2002. Cuenca, UCLM, pp. 165-179; tb. en http://artesescenicas.uclm.es/archivos_subidos/textos/290/teatropostdrama tico_ocornago.pdf (última consulta, 4-6-2016)

CREIG, David (2001): «Introduction», en KANE (2001), pp. ix-xviii.

De Vos, Lauren - SAunders, Graham, eds. (2010): Sarah Kane in Context. Manchester, Manchester University Press.

(2011): Cruelty and Desire in the Modern Theater: Antonin Artaud, Sarah Kane, and Samuel Beckett. London, Lexington Books.

DANAN, Joseph (2001): «Acción(es)», en SARRAZAC, dir. (2011), pp. 37-41.

DeleuZe, Gilles - GuATTARI, Félix (1975): Kafka. Para una literatura menor. Trad. Jorge Aguilar Mora. Madrid, Editorial Nacional, 2002.

DUBATTI, Jorge (2009): «Capitalismo, enfermedad y tragedia», en KANE (1998/2000), pp.7-14.

- (2010): Filosofía del teatro II. Cuerpo poético y función ontológica. Buenos Aires, Atuel.

JÜRS-MUNBY, Karen (2006): «Introduction», en LEHMANN (1999b), pp. 1-15.

KAnE, Sarah (1998/2000): Ansia / 4.48 Psicosis. Trad. Rafael Spregelburd. Buenos Aires, Losada, 2009.

(2001): Complete Plays: Blasted, Phaedra's love, Cleansed, Crave, 4.48 Psychosis, Skin. London, Paperback. 
KristeVA, Julia (1969a): Semiótica 1. Trad. José Martín Arancibia. Caracas, Fundamentos, 2001. (1969b): Semiótica 2. Trad. José Martín Arancibia. Caracas, Fundamentos, 1981.

Lehmann, Hans-Thies (1999a): Teatro Posdramático. Trad. Diana González. México, Paso de Gato - CENDEAC, 2013.

- (1999b): Postdramatic Theatre. Trad. Karen Jürs-Munby. London - New York, Routledge Taylor \& Francis e- Library, 2006.

Pavis, Patrice (1996): Diccionario del teatro: dramaturgia, estética, semiología. Trad. Jaume Melendres. Buenos Aires, Paidós, 2008.

REES, Catherine (2012): «Sarah Kane», en SIERZ, comp. (2012), pp. 112-137.

RosenzVaig, Marcos (2009): El teatro de la enfermedad. Buenos Aires, Biblos.

RYNGAERT, Jean-Pierre (2001): «Personaje (crisis del)», en SARRAZAC, dir. (2011), pp. 167-172.

SÁNCHEZ, José (2013): «Para una lectura posteatral de Teatro posdramático», en LEHMANN (1999a), pp. 17-25.

SARRAZAC, Jean-Pierre, dir. (2001): Léxico del drama moderno y contemporáneo. Trad. Víctor Viviescas. México, Paso de Gato, 2011.

(2006): «El impersonaje. Una relectura de la crisis del personaje», Revista de Literatura:

Teoría, Historia, Crítica, 8, pp.353-369; tb. en http://www.bdigital.unal.edu.co/14118/1/3-7906-

PB.pdf (última consulta, 4-6-2016)

(2011): Juegos de sueño y otros rodeos: alternativas a la fábula en la dramaturgia. Trad. Víctor

Viviescas. México, D. F., Conaculta, 2011.

- (2012): Poétique du drame moderne. De Henrik Ibsen à Bernard-Marie Koltès. Paris, Seuil.

SAUNDERS, Graham (2002): 'Love me or kill me': Sarah Kane and the Theatre of Extremes.

Manchester, Manchester University Press.

- (2009): About Kane: The Playwright and The Work. London, Faber \& Faber.

SIERZ, Aleks (2001): In-Yer-Face Theatre: British Drama Today. London, Paperback.

- comp. (2012): Modern British Playwriting: The 1990s. London, Methuen.

SPREGELBURD, Rafael (2009): «Nota del traductor», en KANE (1998/2000), pp.139-152.

SzONDI, Peter (1956): Teoría del drama moderno (1880-1950). Tentativas sobre lo trágico. Trad. Javier Orduña. Madrid, Dykinson, 2011.

TALENS, Jenaro (1987): «Introducción: El silencio como representación», en Samuel BECKETT, Pavesas. Barcelona, Tusquets Editores, 2000.

Urban, Ken (2001): «An ethic of catastrophe. The theatre of Sarah Kane», PAJ: A Journal of Performance and Art. 69/23, pp. 36-46.

VOITGS-VIRCHOW, Eckart (2010): «'We are anathema’ - Sarah Kane’s plays as postdramatic theatre versus the 'dreary and repugnant tale of sense'», en DE VOS - SAUNDERS, eds. (2010), pp. 195208. 